\title{
Rock brittleness evaluation method based on the complete stress- strain curve
}

\author{
ChenYang Liu, Yong Wang, XiaoPei Zhang, LiZhi Du \\ University of Jilin, Changchun 130012, China \\ wyzrp613@jlu.edu.cn
}

\begin{abstract}
Brittleness plays an important role in the brittle failure process of rocks, and is also one of the important mechanical properties of rocks and a key indicator in rock engineering such as hydraulic fracturing, tunnelling machine borehole drilling and rockburst prediction. Therefore, aiming at the applicability of the brittleness index, this paper summarizes and analyzes the existing brittleness indices based on different experimental methods. Through analysis, it is found that many of the existing methods have their limitations. On the other hand, the brittleness evaluation method based on the stress sstrain curve makes it easier to obtain key parameters and quantify them. Therefore, this paper also adopts this practically widely used method. It proposes a brittleness index based on the post-peak stress drop rate of the rock stress-strain curve and the difficulty of brittle failure, verifies by the traditional triaxial surrounding rock pressure test the accuracy and superiority of $B_{\mathrm{L}}$ and further explores the differences between the brittleness indices $B_{8}$, $B_{11}, B_{12}$ and $B_{\mathrm{L}}$. Finally, the brittleness index $B_{\mathrm{L}}$ and $B_{13}$ are further contrasted by the existing experimental data.
\end{abstract}

KEYwORDS. Rock mechanics; Failure; Brittleness; Complete stress-strain curve.

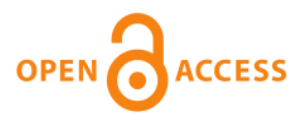

Citation: Liu, C.Y., Wang, Y., Zhang, X.P., Du, L.Z., Rock brittleness evaluation method based on the complete stress-strain curve, Frattura ed Integrità Strutturale, 49 (2019) 557-567.

Received: 07.11.2018

Accepted: 19.02.2019

Published: 01.04 .2019

Copyright: (C) 2019 This is an open access article under the terms of the CC-BY 4.0, which permits unrestricted use, distribution, and reproduction in any medium, provided the original author and source are credited.

\section{INTRODUCTION}

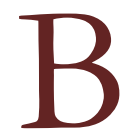
rittleness is a fundamental parameter of rock mechanics and plays an important role in rock failure engineering. For example, the brittleness of rocks is an important indicator to evaluate the risks of rockburst. For underground engineering, rockburst is the most important issue [1]; in tunnel engineering, the rock brittleness determines the excavation efficiency of the TBM shield tunnelling machine; it also determines the efficiency of shale gas and oil production and has a great impact on the hydraulic fracturing of horizontal wells [2-5]. In order to reduce or even prevent the adverse 
effects of disasters on underground engineering and improve mining efficiency, it is extremely important for scientific research to figure out how to accurately evaluate the brittleness of rocks.

\begin{tabular}{|c|c|}
\hline $\begin{array}{c}B_{1}=\sigma_{c} / \sigma_{t}, B_{2}= \\
\left(\sigma_{c}-\sigma_{t}\right) /\left(\sigma_{c}+\sigma_{t}\right) \\
B_{3}=\sigma_{c} \sigma_{t} / 2, B_{4}=\sqrt{B_{3}}\end{array}$ & $\sigma_{c}$ and $\sigma_{t}$ are the UCS and the tensile strength, respectively. \\
\hline $\begin{array}{c}B_{5}=B_{5}^{\prime} B_{5}^{\prime \prime}, B_{5}^{\prime}= \\
\left(\varepsilon_{B R I T}-\varepsilon_{n}\right) /\left(\varepsilon_{m}-\varepsilon_{n}\right) \\
B_{5}^{\prime \prime}=\alpha C S+\beta C S+\eta \\
\mathrm{CS}=\varepsilon_{p}\left(\sigma_{p}-\sigma_{r}\right) / \sigma_{p} / \\
\quad\left(\varepsilon_{r}-\varepsilon_{p}\right)\end{array}$ & $\begin{array}{l}\varepsilon_{B R I T}, \varepsilon_{m}, \varepsilon_{n} \text { are the peak strain, the peak strain maximum and the minimum } \\
\text { value of sample rock specimen, respectively. } \alpha, \beta, \eta \text { are the standardized } \\
\text { coefficients. } \sigma_{p} \text { and } \sigma_{r} \text { are the peak strength and the residual strength, } \\
\text { respectively. } \varepsilon_{p} \text { and } \varepsilon_{r} \text { are the peak strain and the residual strain, respectively. }\end{array}$ \\
\hline $\begin{array}{c}B_{6}=(M-E) / M, B_{7}= \\
E / M\end{array}$ & $\begin{array}{l}\mathrm{M} \text { and } \mathrm{E} \text { are the post-peak modulus and the pro-peak elastic modulus, } \\
\text { respectively. }\end{array}$ \\
\hline $\begin{aligned} B_{8} & =\left(\sigma_{p}-\sigma_{r}\right) / \sigma_{p} \\
B_{9} & =\left(\varepsilon_{r}-\varepsilon_{p}\right) / \varepsilon_{p} \\
& B_{10}=\varepsilon_{R} / \varepsilon_{P}\end{aligned}$ & $\begin{array}{c}\sigma_{p} \text { and } \sigma_{r} \text { are the peak strength and the residual strength, respectively. } \varepsilon_{r} \text { and } \varepsilon_{P} \\
\text { are the peak strain and the residual strain, respectively, } \varepsilon_{R} \text { is the reversible strain } \\
\text { of the stress-strain curve. }\end{array}$ \\
\hline $\begin{array}{c}B_{11}=B_{11}^{\prime} B_{11}^{\prime \prime}, B_{11}^{\prime}= \\
\left(\sigma_{p}-\sigma_{r}\right) / \sigma_{p}, B_{11}^{\prime \prime}= \\
\lg \left|k_{a c}\right| / 10\end{array}$ & $\begin{array}{c}\sigma_{p} \text { and } \sigma_{r} \text { are the peak strength and the residual strength, respectively. } k_{a c} \text { is the } \\
\text { post-peak stress drop rate. }\end{array}$ \\
\hline $\begin{array}{c}B_{12}=B_{12}^{\prime}+B_{12}^{\prime \prime}, B_{12}^{\prime}= \\
\left(\sigma_{p}-\sigma_{r}\right) /\left(\varepsilon_{r}-\varepsilon_{p}\right) \\
B_{12}^{\prime \prime}=\left(\sigma_{p}-\sigma_{r}\right)\left(\varepsilon_{r}-\right. \\
\left.\varepsilon_{p}\right) /\left(\sigma_{p} \varepsilon_{p}\right)\end{array}$ & $\begin{array}{c}\sigma_{p} \text { and } \sigma_{r} \text { are the peak strength and the residual strength, respectively, } \varepsilon_{p} \text { and } \varepsilon_{r} \\
\text { are the peak strain and the residual strain, respectively. }\end{array}$ \\
\hline $\begin{array}{c}B_{13}=B_{13}^{\prime}+B_{13}^{\prime \prime}, B_{13}^{\prime}= \\
\varepsilon_{p}\left(\sigma_{\mathrm{p}}-\sigma_{\mathrm{i}}\right) /\left(\varepsilon_{p}-\varepsilon_{\mathrm{i}}\right) \sigma_{p} \\
\quad B_{13}^{\prime \prime}= \\
\varepsilon_{p}\left(\sigma_{\mathrm{p}}-\sigma_{\mathrm{r}}\right) / \sigma_{p}\left(\varepsilon_{r}-\right. \\
\left.\varepsilon_{p}\right)\end{array}$ & $\begin{array}{c}\sigma_{p} \text { and } \sigma_{r} \text { are the peak strength and the residual strength, respectively. } \varepsilon_{p} \text { and } \varepsilon_{r} \\
\text { are the peak strain and the residual strain, respectively, } \sigma_{\mathrm{i}} \text { and } \varepsilon_{\mathrm{i}} \text { are the crack } \\
\text { initiation stress and the crack initiation strain }\end{array}$ \\
\hline $\begin{array}{c}B_{14}=\sin \beta, B_{15}= \\
45^{\circ}+\beta / 2\end{array}$ & $\beta$ is the inner friction angle determined from Mohr's envelope. \\
\hline $\begin{array}{c}B_{16}=0.5 E_{\text {brit }}+ \\
0.5 \mu_{\text {brit }}, E_{\text {brit }}=(E- \\
1) /(8-1) \times \\
100, \mu_{\text {brit }}=(0.4-1) / \\
(0.4-0.15)\end{array}$ & $\mathrm{E}$ and $\mu$ are the post-peak modulus and the elastic modulus, respectively. \\
\hline$B_{17}=\left(H_{\mu}-H_{m}\right) / c$ & $\begin{array}{l}\text { where } H_{\mu} \text { is the micro-indentation hardness, } H_{m} \text { is the macro-indentation } \\
\text { hardness, and } c \text { is the constant }\end{array}$ \\
\hline$B_{18}=H_{a} / K_{c}$ & where $H_{a}$ is hardness and $K_{c}$ is fracture toughness. \\
\hline$B_{19}=H_{a} E / K_{c}^{2}$ & where $H_{\mathrm{a}}$ and $K_{\mathrm{c}}$ are same as those in $B_{18}, E$ is Young's modulus \\
\hline $\begin{array}{c}B_{19}=W_{q t z} /\left(W_{q t z}+\right. \\
\left.W_{\text {carb }}+W_{\text {clay }}\right)\end{array}$ & $\begin{array}{c}W_{q t,} W_{c a r b} \text { and } W_{c l a y} \text { are the content of quartz, clay and carbonate minerals, } \\
\text { respectively. }\end{array}$ \\
\hline
\end{tabular}

Table 1: Formula meaning and explanation. 
However, there is currently no standard or widely accepted concept for the evaluation of the rock brittleness index. Researchers hold different views for different research purposes. Morley [6] and Hetényi [7] argue that rock brittleness is characterized by low elongation or low strain value due to the lack of ductility or compressibility. Ramasy [8] defines brittleness as the loss of cohesion in a rock as it deforms within the elastic range. Similarly, Obert and Duaval [9] consider brittleness to be a phenomenon in which a material (such as cast iron or rock) breaks or only slightly exceeds the yield stress. Tarasov and Potvin [10] proposed that brittleness is the ability to self-maintain the macroscopic damage in the post-peak area under the compressive load due to the accumulation of elastic energy. With the development of rock mechanics, a lot of research has been done on the evaluation of rock brittleness, and the commonly used evaluation methods are shown in Tab. 1.

\section{Brittleness evaluation method based on the rock stress-strain curve}

In Tab. 1, the brittleness indices $B_{1}-B_{4}$ are proposed based on the relationship between UCS (uniaxial compressive strength) and uniaxial tensile strength. According to the experimental results, Kahraman [11] believed that the penetration rate of the rotary drill bit has a strong exponential relationship with the brittleness indices $B_{1}$ and $B_{2}$. Altindag [12] proposed the brittleness indices $B_{3}-B_{4}$ based on the tensile-compressive strength curve to quantitatively evaluate the brittleness of rocks. These two indices are often used to predict the drillability of rocks. However, the brittleness indices $B_{1}-B_{4}$ based on UCS and uniaxial tensile strength is not applicable to the analysis of rock brittleness under complex stress conditions. According to the post-peak stress drop rate and peak strength, Li Qinghui et al [13] proposed the brittleness index $B_{5}$, which is based on the three standard coefficients for the post-peak stress drop, but only applies to a certain type of rocks, and what is more, a lot of experiments need to be done to obtain an accurate value. At the same time, Tarasov and Potvin [14] proposed the brittleness indices $B_{6}-B_{7}$ based on the post-peak secant modulus and the pre-peak elastic modulus. Xia Yingjie believed that these two brittleness indices cannot effectively distinguish the brittle characteristics of different stress-strain curves [15]. R. Altindag [16] proposed the brittleness indices $B_{7}$ and $B_{8}$ based on the peak stress-strain and residual stress-strain relations. Hucka and Das [17] proposed the brittleness indices $B_{10}$ based on the ratio of recoverable strain to peak strain before the peak; however, these methods consider only a few mechanical parameters and cannot fully reflect the strain-strain process of the entire rock. Therefore, these methods require further improvement. Meng et al. [18] proposed the brittleness index $B_{11}$ based on the relative magnitude and absolute rate of the post-peak stress drop, and further verified the accuracy of the index by doing comparison test on different types of rocks under different surrounding rock pressures, but this index does not represent the pre-peak mechanical characteristics.

Xia Yingjie et al. proposed the brittleness index $B_{12}$ based on the post-peak stress drop rate and the ratio of the elastic energy released by the instability failure to the total energy stored before the peak. Chen Guoqing et al. [19] proposed the rock brittleness index $B_{13}$ based on the post-peak stress drop rate and the stress growth rate between the pre-peak initiation stress and the peak stress. The method uses the stress growth rate between the initiation stress and the peak stress to characterize the pre-peak brittle state. At present, there are two effective ways to determine the initiation stress, one being acoustic emission and the other based on the strain inflection point of the crack volume [20]. Acoustic emission is often affected by noise, making it difficult to determine the moment of crack initiation. The second method, which determines the initiation stress through the strain inflection point of the crack volume, often depends on the mineral composition and particle size, so it is also difficult to determine an accurate value. In order to further verify the accuracy of the method proposed in this paper, the following section will make comparisons with the experimental data by Chen Guoqing et al.

\section{Brittleness evaluation method based on internal friction angle}

Hucka and Das [21] proposed evaluating the brittleness indices $B_{14}$ and $B_{15}$ of rocks considering the internal friction angle. At the same time, Tarasov and Potvin [22] found through experiments that the brittleness index $B_{13}$ is positively correlated with the rock fracture angle. However, the brittleness indices $B_{14}$ and $B_{15}$ only apply to the same type of rocks; and it is also difficult to obtain an accurate rock fracture angle.

Brittleness evaluation method based on elastic modulus and Poisson's ratio

Rockman et al. [23] proposed the brittleness index $B_{16}$ based on shale reservoir; however, the brittleness index $B_{16}$ only takes into account the elastic modulus and Poisson's ratio, but ignores many important mechanical parameters. In order to obtain accurate parameters, mechanical experiments still need to be conducted on a lot of rock samples. All these factors limit the development of the brittleness index $B_{16}$. 


\section{Brittleness evaluation method based on hardness}

Hucka and Das proposed a rock brittleness evaluation method based on the difference between rock micro-hardness and macro-hardness. Lawn and Marshall [24] established the brittleness index $B_{18}$ for the ceramic engineering field. Quinn and Quninn [25] described an index $B_{19}$ to measure the rock brittleness based on the ratio of the deformation energy per unit volume to the fracture surface energy per unit area. This brittleness evaluation index considers too few factors and is only applicable to the ceramic field, so its accuracy and applicability should be further considered in applications.

\section{ROCK BRITTLENESS INDEX BASED ON STRESS-STRAIN DROP AND PEAK STRAIN}

$\mathrm{I}$ $\mathrm{n}$ the brittleness evaluation in hydraulic fracturing and rockburst prediction, the existing brittleness evaluation methods consider only a few mechanical parameters. What is more, many of them are only applicable to uniaxial load conditions, and not suitable for high surrounding rock pressure in deep tunnel construction. The stress-strain curve, on the other hand, reflects the whole process of the rock from deformation failure to the ultimate loss of bearing capacity under external load, and is applicable to the state analysis of rock failure under surrounding rock pressure. Based on the stress-strain curve of the rock failure, quantitative brittleness parameters can be obtained. Therefore, the post-peak stress-strain shape obtained in the laboratory is the main method for researchers to qualitatively understand the rock brittleness. Based on the above, this paper proposes a brittleness evaluation method based on post-peak stress drop rate and pre-peak brittle failure.

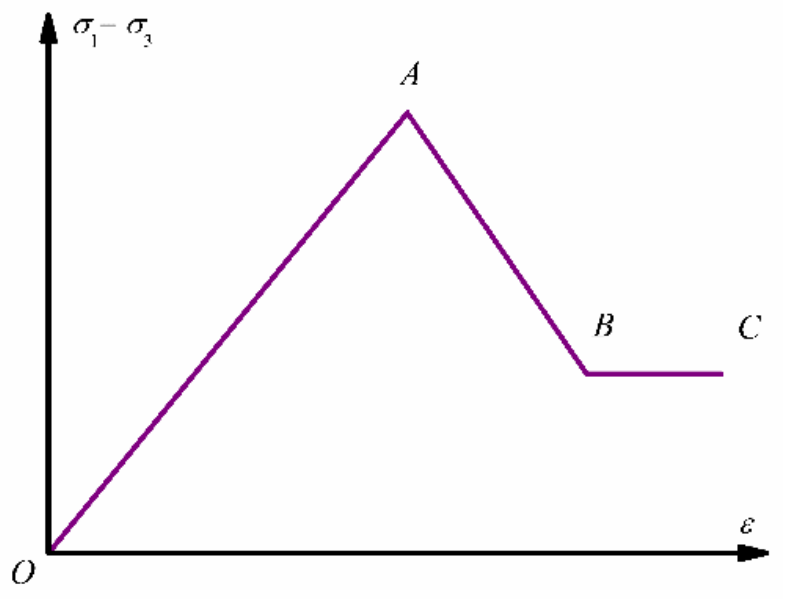

Figure 1: Simplified stress-strain curve

In Fig. 1, the polyline OABC is a simplified Class I stress-strain curve. Point $\mathrm{A}\left(\sigma_{p}, \varepsilon_{p}\right)$ corresponds to the peak point, and $\sigma_{P}$ and $\varepsilon_{P}$ are the peak intensity and the peak strain, respectively; point $\mathrm{B}\left(\sigma_{r}, \varepsilon_{r}\right)$ corresponds to the residual point, and $\sigma_{r}$ and $\varepsilon_{r}$ are the residual stress and the residual strain, respectively. It is obvious in Fig. 1 that the polyline OABC is divided by point $\mathrm{A}\left(\sigma_{p}, \varepsilon_{p}\right)$ and point $\mathrm{B}\left(\sigma_{r}, \varepsilon_{r}\right)$, so that the corresponding mechanical parameters can be quantitatively obtained. The drawbacks of the brittleness indices $B_{10}-B_{11}$ are already discussed above. Based on these two methods, this paper proposes a new method $B_{\mathrm{L} 1}$, which considers both the stress drop $B_{8}$ and the strain drop $B_{9}$. At the same time, the faster the stress drop rate, the higher the brittleness, so the difference between the peak stress and the residual stress is proportional to the brittleness index and the difference between the peak strain and the residual strain is inversely proportional to the brittleness index. In addition, in order to emphasize the final increase of the post-peak strain, the residual strain is used to replace the peak strain in the denominator of the brittleness index $B_{9}$.

First, the post-peak brittleness index $B_{\mathrm{L} 1}$ is:

$$
B_{\mathrm{L} 1}=\frac{\frac{\sigma_{\mathrm{p}}-\sigma_{\mathrm{r}}}{\sigma_{\mathrm{p}}}}{\frac{\varepsilon_{\mathrm{r}}-\varepsilon_{\mathrm{p}}}{\varepsilon_{\mathrm{r}}}}
$$


where, $\varepsilon_{\mathrm{r}}$ and $\varepsilon_{\mathrm{p}}$ are the residual strain and the peak strain, respectively; $\sigma_{\mathrm{p}}$ and $\sigma_{\mathrm{r}}$ are the peak stress and the residual stress, respectively.

Peak strain can reflect the difficulty of brittle failure [23]. In addition, according to previous studies, as the peak strain increases, the rock tends to transition from being brittle to being ductile, i.e., the brittleness index will become lower. Considering this factor, it is proposed that the pre-peak brittleness index $B_{\mathrm{L} 2}$ should be the reciprocal of the peak strain. Second, the index of the difficulty of pre-peak brittle failure is as follows:

$$
B_{\mathrm{L} 2}=\frac{1}{\varepsilon_{\mathrm{P}}}
$$

Based on this, the new rock brittleness index $B_{\mathrm{L}}$ considers both the post-peak stress drop rate and the difficulty of pre-peak brittle failure.

Finally, the brittleness index $B_{\mathrm{L}}$ is expressed as follows:

$$
B_{\mathrm{L}}=B_{\mathrm{L} 1} B_{\mathrm{L} 2}
$$

In summary, the new rock brittleness evaluation method $B_{\mathrm{L}}$ considers the post-peak stress drop rate and also introduces the residual strain to emphasize the final increase of post-peak strain. Moreover, it incorporates the difficulty of brittle failure to characterize the pre-peak brittle characteristics.

\section{COMPARISON AND VERIFICATION OF BRITTLENESS INDICES}

$\mathrm{C}$ onsidering the great impact of surrounding rock pressure on rock brittleness in underground engineering, this section will explore the variations of rock brittleness under different surrounding rock pressure conditions. In order to verify the accuracy of the brittleness index $B_{\mathrm{L}}$, Tab. 2 determines the relevant mechanical parameters and calculates the brittleness index $B_{\mathrm{L}}$ according to the stress-strain curve in Fig. 4 . At the same time, for comparison with other brittleness indices, the brittleness indices $B_{6}-B_{12}$ and $B_{14}$ are selected from Tab. 1 (as $B_{13}$ needs initiation stress and initiation strain, it is not selected here for comparison. The following sections will use the data by Chen Guoqing et al. for further

\begin{tabular}{|c|c|c|c|c|c|c|c|c|c|c|c|c|c|c|c|}
\hline $\begin{array}{c}\text { Confining } \\
\text { pressure } \\
/ \mathrm{MPa}\end{array}$ & $\begin{array}{c}\sigma_{\mathrm{p}} / \\
(100 \mathrm{MPa})\end{array}$ & $\varepsilon_{\mathrm{p}} / 10^{-3}$ & $\begin{array}{c}\sigma_{\mathrm{r}} / \\
(100 \mathrm{MPa})\end{array}$ & $\varepsilon_{\mathrm{r}} / 10^{-3}$ & $\varepsilon_{\mathrm{R}} / 10^{-3}$ & $\begin{array}{l}\text { Rupture } \\
\text { angle }\left(^{\circ}\right)\end{array}$ & $B_{6}$ & $B_{7}$ & $B_{8}$ & $B_{9}$ & $B_{10}$ & $B_{11}$ & $B_{12}$ & $B_{14}$ & $B_{\mathrm{L}}$ \\
\hline 0 & 0.419 & 2.59 & 0.268 & 3.47 & 1.656 & 85 & 0.037 & 0.963 & 0.361 & 0.340 & 0.639 & 0.081 & 0.294 & 0.996 & 0.549 \\
\hline 3 & 0.467 & 2.71 & 0.363 & 4.23 & 2.106 & 79 & -1.549 & 2.549 & 0.223 & 0.561 & 0.777 & 0.041 & 0.194 & 0.982 & 0.229 \\
\hline 9 & 0.586 & 3.39 & 0.484 & 4.5 & 2.799 & 75 & -0.908 & 1.908 & 0.174 & 0.327 & 0.826 & 0.034 & 0.149 & 0.966 & 0.208 \\
\hline 12 & 0.605 & 3.63 & 0.357 & 4.9 & 2.142 & 70 & 0.080 & 0.920 & 0.410 & 0.350 & 0.590 & 0.094 & 0.339 & 0.939 & 0.436 \\
\hline 15 & 0.658 & 3.84 & 0.563 & 5.26 & 3.286 & 70 & -1.793 & 2.793 & 0.144 & 0.370 & 0.856 & 0.026 & 0.120 & 0.939 & 0.139 \\
\hline 18 & 0.7956 & 4.51 & 0.677 & 6.12 & 3.837 & 65 & -1.657 & 2.657 & 0.149 & 0.357 & 0.851 & 0.028 & 0.127 & 0.906 & 0.126 \\
\hline 25 & 0.982 & 5 & 0.8085 & 7.79 & 4.117 & 60 & -2.292 & 3.292 & 0.177 & 0.558 & 0.823 & 0.032 & 0.161 & 0.866 & 0.099 \\
\hline
\end{tabular}
comparison).

Table 2: Conventional triaxial compression experimental data of rock specimens from phyllite

\section{Preparation and experimental conditions of rock samples}

Rock brittleness has a profound effect on the stability of deep buried tunnels. In order to accurately evaluate the brittleness of rocks, the effects of surrounding rock pressure must be considered. This paper takes the phyllite samples obtained from 
a deep hole in a tunnel in southwest China as the object. Considering the geostress conditions of the rock samples, the conventional triaxial compression test was carried out to verify the accuracy of the new brittleness index $B_{\mathrm{L}}$. This test was carried out using a MTS 815 test machine under different surrounding rock pressures. Considering the different depths at which the rock samples were taken, 6 surrounding rock pressures were set, which are namely $0,3,9,12,15,18$ and $25 \mathrm{MPa}$. According to the regulations of the International Society for Rock Mechanics, samples were processed into standard specimens with a height of $100 \mathrm{~mm}$ and a diameter of $50 \mathrm{~mm}$. During the experiment, the axial and radial deformations of the sensor were connected to a computer. The surrounding rock pressure was loaded at a rate of $0.1 \mathrm{MPa} / \mathrm{s}$, and the axial force is subject to displacement control, with a loading rate of $0.002 \mathrm{~mm} / \mathrm{s}$.

\section{Comparison and verification of rock brittleness indices under different surrounding rock pressures}

The information on sample loading and deformation is collected and stored by the data acquisition system. The failure results and stress-strain curves of the rock samples are shown in Fig. 2.

Fig. 2 shows the fracture characteristics of the rock samples under different surrounding rock pressures. The macroscopic forms of rock failure mainly include shear-sliding failure along the schistose structure, transverse failure along the schistose surface and composite failure sliding along the schistose surface. As the surrounding rock pressure increased, the fracture angle of the rock sample and the roughness of the fracture surface decreased significantly, and the failure mode of the rock also changed. And with the surrounding rock pressure increasing, the post-peak stress drop rate decreased significantly, and the rock tended to transition from being brittle to being ductile. The experimental results indicate that the brittleness index decreases as the surrounding rock pressure increases. In particular, the rock sample under a surrounding rock pressure of $12 \mathrm{MPa}$ had a very rough fracture surface. Through observation of the rock sample after the test, it is found that it was due to the internal defects in this rock sample. Fig. 3 shows the variations of different brittleness indices as the surrounding rock pressure increases according to the calculation results in Tab. 2.

Based on the experimental results, the rock brittleness index should satisfy the following characteristics: (1) the brittleness anomaly caused by the internal defects of the core under a surrounding rock pressure of $12 \mathrm{MPa}$; (2) the brittleness tends to decrease with the increase of the surrounding rock pressure. From Fig. 5, it can be seen that the brittleness indices $B_{8}, B_{11}$, $B_{12}$ and $B_{\mathrm{L}}$ basically conform to these two characteristics.

For the brittleness indices $B_{6}$ and $B_{7}$, as the surrounding rock pressure increases, they cannot reflect the transition of the rock from brittleness to ductility. This is because the brittleness index $B_{6}$ only considers the post-peak elastic modulus and the pre-peak elastic modulus. For the brittleness index $B_{9}$, it can be clearly seen from Fig. 5 that it does not reflect the brittleness changes. This is because $B_{9}$ only considers the effect of the strain state, but ignores the effect of stress on the brittleness index. $B_{10}$ only considers the recoverable strain and peak strain before the peak, but ignores the post-peak brittle characteristics.

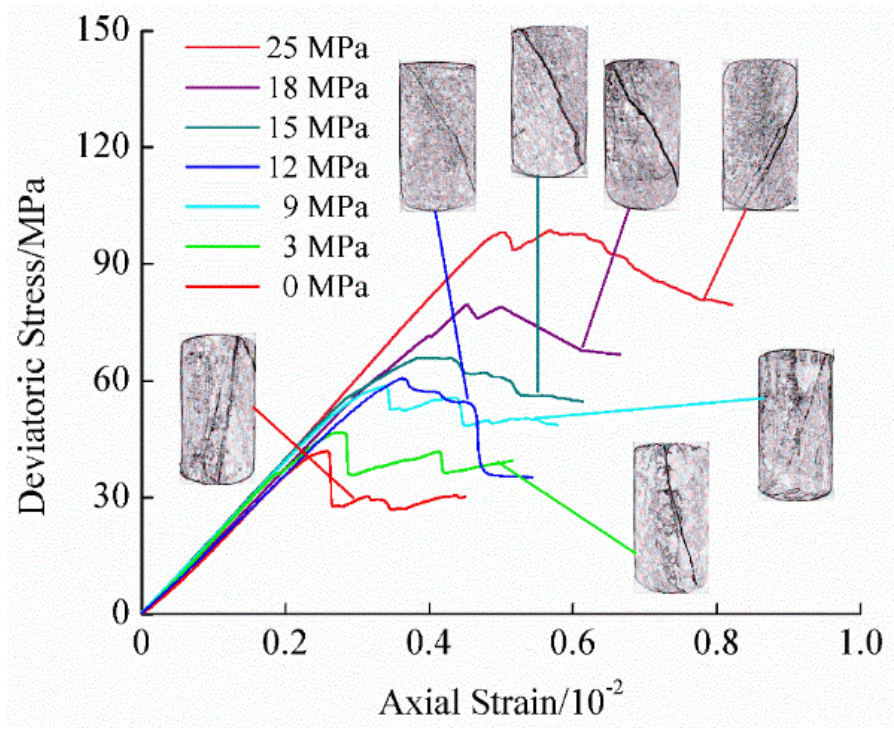

Figure 2: Stress-strain curve of rock samples under different surrounding rock pressures. 
As shown in Fig. 3, the brittleness index $B_{14}$ cannot reflect the brittleness anomaly caused by the internal defects of the sample under a surrounding rock pressure of $12 \mathrm{MPa}$. In addition, it is difficult to quantitatively obtain an accurate rock fracture angle, which may also limit the development of the brittleness index $B_{13}$.

Brittleness indices $B_{8}, B_{11}, B_{12}$ and $B_{\mathrm{L}}$ can reflect the decrease trend of the brittleness index with the increasing surrounding rock pressure and the brittleness anomaly caused by the internal defects of rock samples under a surrounding rock pressure of $12 \mathrm{MPa}$. The next section will further compare the brittleness indices $B_{8}, B_{11}, B_{12}$ and $B_{\mathrm{L}}$ based on the results of the experiment.

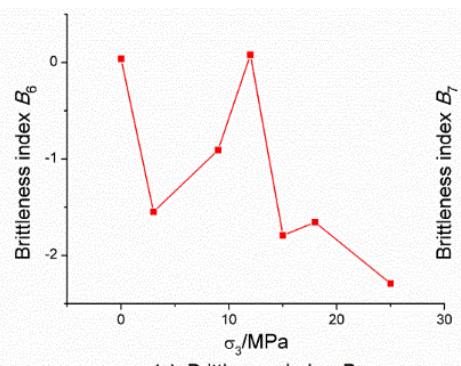

(a) Brittleness index $B_{6}$

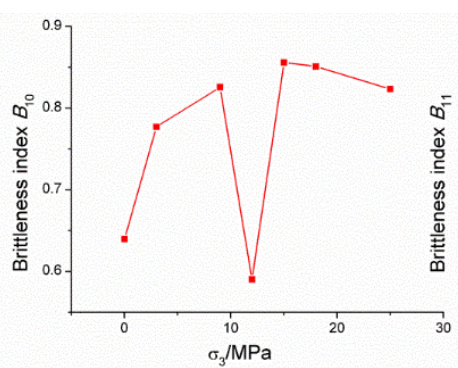

(e) Brittleness index $B_{10}$

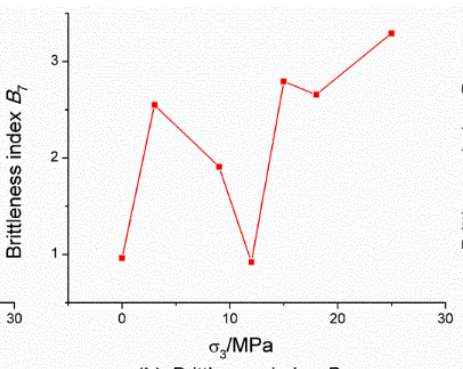

(b) Brittleness index $B_{7}$

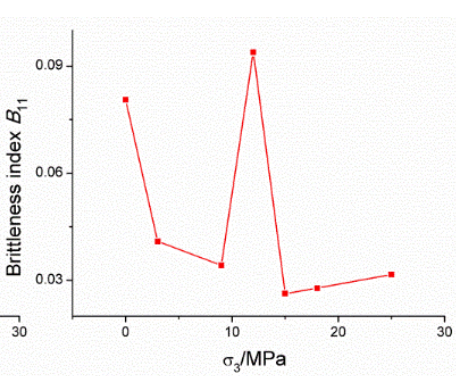

(f) Brittleness index $B_{11}$

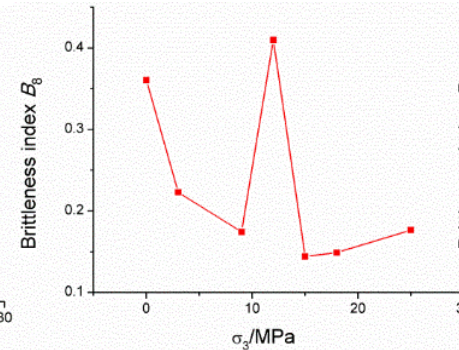

(c) Brittleness index $B_{8}$

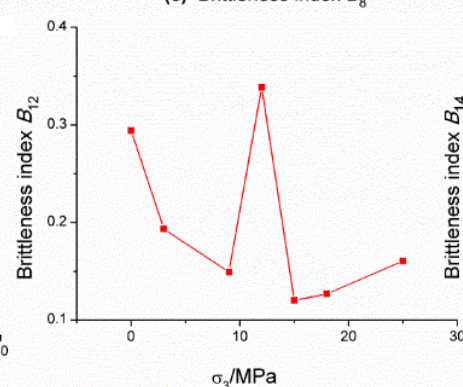

(g) Brittleness index $B_{12}$

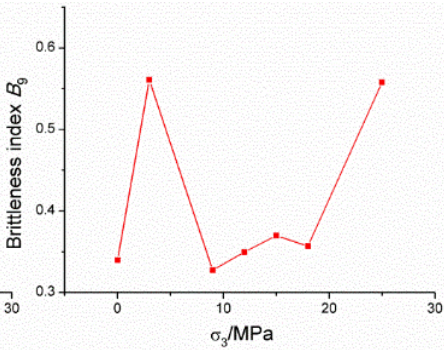

(d) Brittleness index $B_{9}$

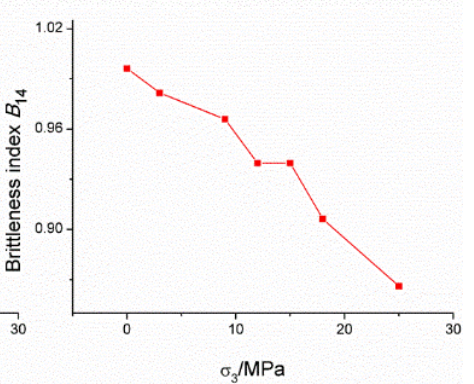

(h) Brittleness index $B_{14}$

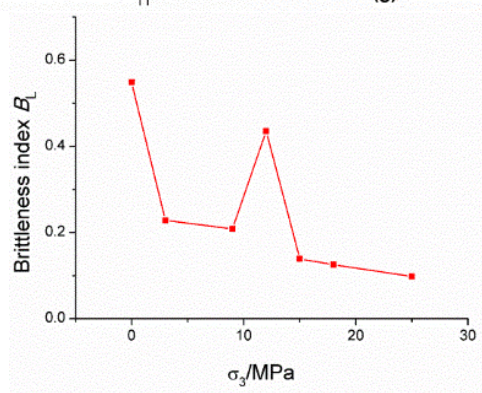

(i) Brittleness index $B_{\mathrm{L}}$

Figure 3: Variations of the core brittleness indices $B_{\mathrm{L}}, B_{14}$ and $B_{6}-B_{12}$ with the surrounding rock pressure

From the above analysis, it can be seen that the brittleness index $B_{\mathrm{L}}$ proposed in this paper is in good consistency with $B_{8}$, $B_{11}$ and $B_{12}$. In order to further compare these brittleness indices, the failure characteristics are analyzed under the surrounding rock pressure of $0-12 \mathrm{MPa}$ and $12-25 \mathrm{MPa}$.

Fig. 4 shows the test results of the core under the surrounding rock pressure of $0 \mathrm{MPa}$ and $12 \mathrm{MPa}$, where the red lines represent the fracture surfaces. As can be seen from Fig. 6, the fracture surface of core a is rougher than that of core b, with a larger fracture angle. In summary, core a is more brittle than core $b$.

The brittleness indices $B_{8}, B_{11}, B_{12}$ and $B_{\mathrm{L}}$ are not consistent with the above analysis results. However, the brittleness index $B_{\mathrm{L}}$ can better reflect the changes.

Fig. 5 shows the test results of cores c, d, and e under the surrounding rock pressure of 15,18 and 25MPa, where the red lines represent the fracture surfaces. The fracture angels of core c, $\mathrm{d}$ and e are $70^{\circ}, 65^{\circ}$ and $60^{\circ}$, respectively. As can be seen from Fig. 7, in the three groups of samples, the roughness of the fracture surface gradually decreases from core c to e, so does the penetration. The fracture surface of core $\mathrm{c}$ penetrates the entire core, but those of cores $\mathrm{d}$ and e do not penetrate 
them. In addition, the fracture angles of the cores are also gradually reduced. In summary, as the surrounding rock pressure increases, the core brittleness gradually decreases, but through the analysis of Fig. 5, it is found that only the brittleness index $B_{\mathrm{L}}$ satisfies this feature under a surrounding rock pressure range of $15 \mathrm{MPa}-25 \mathrm{MPa}$. Therefore, the brittleness index $B_{\mathrm{L}}$ is an effective supplement to $B_{8}, B_{11}$ and $B_{12}$.

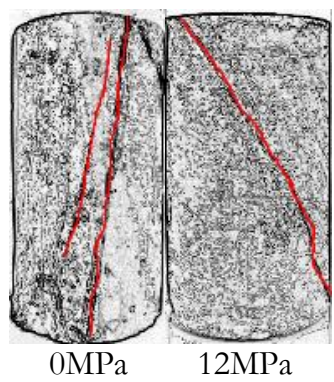

(a) (b)

Figure 4: Mechanical Test Results of Two Groups of Cores

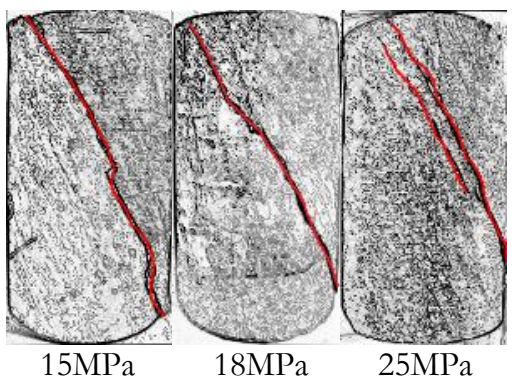

(c) (d) (e)

Figure 5: Mechanical Test Results of Three Groups of Cores

In addition, since it is difficult to obtain the accurate crack initiation stress and crack initiation strain during the test, the following section will use the experimental results of Chen Guoqing et al. to further compare and verify the brittleness indices $B_{\mathrm{L}}$ and $B_{13}$.

\section{FURTHER VERIFICATION OF THE ACCURACY AND APPLICABILITY OF THE BRITTLENESS INDEX B $_{\mathrm{L}}$ UNDER SURROUNDING ROCK PRESSURE}

1 his section will further verify the accuracy and applicability of the brittleness index $B_{\mathrm{L}}$ based on the existing experimental data. Tab. 3 shows the brittleness index $B_{\mathrm{L}}$ calculated according to the experimental data of marble cores under different surrounding rock pressures obtained by Chen Guoqing et al.. At the same time, this paper draws the plots of the brittleness indices $B_{\mathrm{L}}$ and $B_{13}$ changing with the surrounding rock pressure in order to facilitate the comparison with the brittleness index $B_{13}$, as shown in Fig. 6.

\begin{tabular}{lllllllll}
\hline $\begin{array}{l}\text { Confining } \\
\text { pressure }\end{array}$ & $\sigma_{\mathrm{i}} / \mathrm{MPa}$ & $\varepsilon_{i} / 10^{-3}$ & $\sigma_{\mathrm{p}} / \mathrm{MPa}$ & $\varepsilon_{\mathrm{p}} / 10^{-3}$ & $\sigma_{\mathrm{r}} / \mathrm{MPa}$ & $\varepsilon_{\mathrm{r}} / 10^{-3}$ & $B_{13}$ & $B_{\mathrm{L}}$ \\
$\mathrm{MPa}$ & & & & & & & & \\
5 & 87.929 & 1.693 & 192.084 & 3.729 & 71.956 & 5.976 & 2.031 & 0.446 \\
15 & 89.354 & 1.589 & 258.749 & 4.867 & 123.939 & 7.434 & 1.960 & 0.310 \\
25 & 116.041 & 1.967 & 297.072 & 5.615 & 162.811 & 8.174 & 1.930 & 0.257 \\
35 & 126.055 & 1.943 & 332.891 & 6.393 & 190.99 & 10.716 & 1.523 & 0.165 \\
\hline
\end{tabular}

Table 3: Mechanical parameters of cores and calculation results of brittleness indices $B_{13}$ and $B_{\mathrm{L}}$ under surrounding rock pressure 


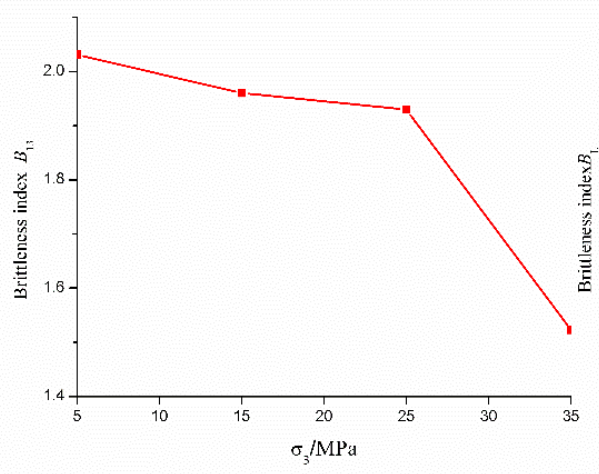

(a) Brittleness index $B_{13}$

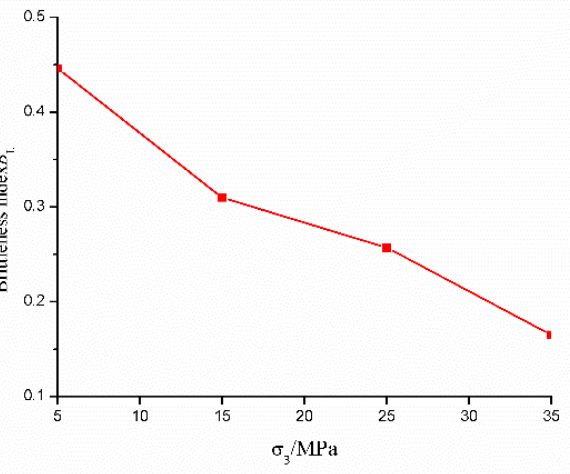

(b) Brittleness index $B_{\mathrm{L}}$.

Figure 6: Changes of the marble brittleness indices under different surrounding rock pressures

The brittleness index $B_{\mathrm{L}}$ meets the feature that the brittleness decreases as the surrounding rock pressure increases. In addition, as the surrounding rock pressure increases, the decrease of the brittleness index $B_{\mathrm{L}}$ is more linear than $B_{13}$, which is more in line with the actual test results. For $B_{13}$, the variation interval is not large, making it difficult to quantitatively measure the changes of brittleness. On the contrary, $B_{\mathrm{L}}$ changes more significantly, which is also more in line with the actual test results. In summary, the brittleness index $B_{\mathrm{L}}$ can give a more accurate quantitative description of rock brittleness and more accurately reflect its variations.

In order to further explore the applicability of the brittleness index $B_{\mathrm{L}}$ to different types of rocks under surrounding rock pressure and compare it with $B_{13}$, this paper calculates the brittleness index $B_{\mathrm{L}}$ according to the experimental data of different rocks under the surrounding rock pressure of $30 \mathrm{MPa}$ obtained by Chen Guoqing et al., as listed in Tab. 4, and draws the brittleness index variations of 5 types of rock samples under the tri-axial stress condition, as shown in Fig. 7.

\begin{tabular}{lllllllll}
\hline Rock sample type & $\sigma_{\mathrm{i}} / \mathrm{MPa}$ & $\varepsilon_{i} / 10^{-3}$ & $\sigma_{\mathrm{p}} / \mathrm{Mpa}$ & $\varepsilon_{\mathrm{p}} / 10^{-3}$ & $\sigma_{\mathrm{r}} / \mathrm{MPa}$ & $\varepsilon_{\mathrm{r}} / 10^{-3}$ & $B_{13}$ & $B_{\mathrm{L}}$ \\
marble & 75.917 & 1.515 & 134.521 & 11.24 & 126.537 & 24.337 & 0.554 & 0.010 \\
sandstone & 106.045 & 3.596 & 245.677 & 11.382 & 144.481 & 21.565 & 1.291 & 0.079 \\
limestone & 248.161 & 9.669 & 286.085 & 12.767 & 198.059 & 18.385 & 1.245 & 0.077 \\
coarse grain granite & 120.904 & 3.79 & 291.095 & 11.226 & 133.415 & 20.598 & 1.531 & 0.106 \\
fine grain granite & 145.194 & 1.93 & 476.75 & 8.8 & 9.716 & 22.212 & 1.534 & 0.184 \\
\hline
\end{tabular}

Table 4: Mechanical parameters and calculated brittleness indices $B_{13}$ and $B_{\mathrm{L}}$ of different rocks under surrounding rock pressure [18]

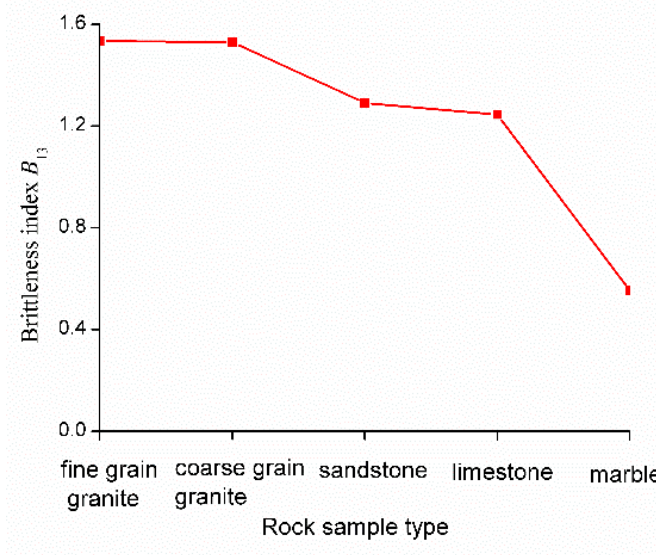

(a) Brittleness index $B_{13}$

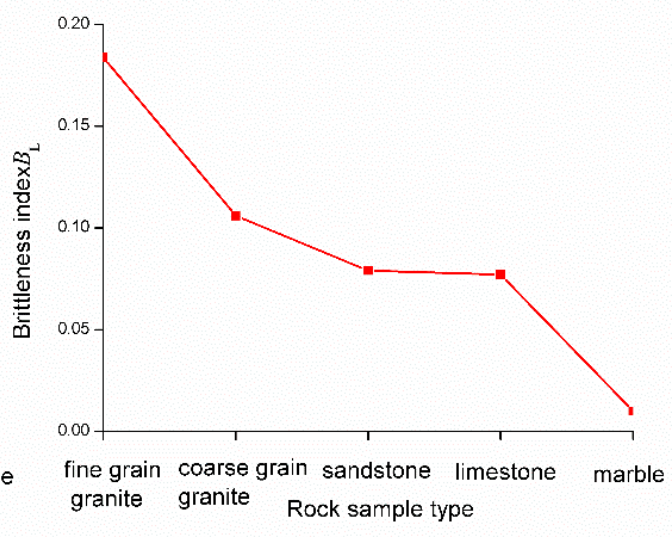

(b) Brittleness index $B_{\mathrm{T}}$

Figure 7: Brittleness index variations of the 5 types of rocks under surrounding rock pressure 
As shown in Fig. 7 , the brittleness index $B_{\mathrm{L}}$ satisfies the degree of brittleness: fine grain granite $>$ coarse grain granite $>$ sandstone $>$ limestone $>$ marble. The brittleness indices $B_{\mathrm{L}}$ and $B_{13}$ of marble are significantly lower than those of the other four types of rock samples, which is consistent with the experimental results. For the other four types of rocks, the differences of the brittleness index $B_{\mathrm{L}}$ are more obvious, making it much easier to quantitatively measure the degree of brittleness and also better reflect the brittleness variation trends of different rock samples.

Section 4 further verifies the accuracy and applicability of the brittleness index $B_{\mathrm{L}}$ by using the experimental results of the same type and different types of rocks under surrounding rock pressure. Compared with the brittleness index $B_{13}, B_{\mathrm{L}}$ is applicable to the brittleness evaluation in both cases.

\section{CONCLUSIONS}

$\Lambda$ ccurate evaluation of rock brittleness is of great importance in rock engineering, such as underground tunnel excavation and hydraulic fracturing and so on. This paper proposes a new brittleness index evaluation method $B_{\mathrm{L}}$ and verifies its effectiveness with experimental results. In addition, it also verifies the accuracy and applicability of the method using the existing experimental data. Through systematic discussion and analysis of rock brittleness, this paper finally obtains the following conclusions:

1. This paper proposes a new brittleness evaluation method $B_{\mathrm{L}}$ based on the post-peak stress drop rate and the difficulty of the pre-peak brittle failure. It verifies the accuracy of this index using the experimental results of phyllite rock samples taken from a deep hole of a tunnel in Southwest China. With the experimental results, this paper further compares $B_{\mathrm{L}}$ with other brittleness indices $B_{8}, B_{11}$ and $B_{12}$, and concludes that $B_{\mathrm{L}}$ more accurately reflects the experimental results.

2. With the experimental results of different types of rocks under surrounding rock pressure, this paper compares the brittleness indices $B_{13}$ and $B_{\mathrm{L}}$ and finds that $B_{\mathrm{L}}$ accurately reflects the true brittleness variation trend of different rocks under surrounding rock pressure; at the same time, it also explores the brittleness changes of the same type of rocks under different surrounding rock pressures and finds that $B_{\mathrm{L}}$ can give a better quantitative description of the rock brittleness than $B_{13}$. 3. By analyzing the core with a surrounding rock pressure of $12 \mathrm{MPa}$, this paper finds that the internal defects of a rock have an important impact on the rock mechanics. In actual engineering, the internal defects of rocks should be used to the advantage of rock engineering, and attention should be paid to make sure these internal defects will not cause any serious engineering disaster.

\section{REFERENCES}

[1] Altindag, R. (2002). The evaluation of rock brittleness concept on rotary blast hold drills, Journal of the Southern African Institute of Mining and Metallurgy, 102, pp. 61-66.

[2] Holt, R.M., Fjær, E., Stenebråten, J.F., Nes, O.M. (2015). Brittleness of shales: relevance to borehole collapse and hydraulic fracturing, Journal of Petroleum Science and Engineering, 131, pp. 200-209.

DOI: $10.1016 /$ j.petrol.2015.04.006

[3] Hajiabdolmajid, V., Kaiser, P. (2003). Brittleness of rock and stability assessment in hard rock tunneling, Tunnelling and Underground Space Technology, 18, pp. 35-48.

[4] Dursun, A.E., Gokay, M.K. (2016.) Cuttability assessment of selected rocks through different brittleness values, Rock Mechanics and Rock Engineering, 49, pp. 1173-1190. DOI:10.1007/s00603-015-0810-2.

[5] Özfirat, M.K., Yenice, H., Şimşir, F., Yaralı, O. (2016). A new approach to rock brittleness and its usability at prediction of drillability, Journal of African Earth Sciences, 119, pp. 94-101. DOI: 10.1016/j.jafrearsci.2016.03.017.

[6] Morley, A. (1944). Strength of Material, Longman, Green, London.

[7] EL-Ebrashi, M.K., Craig, R.G., Peyton, F.A. (1969). Experimental stress analysis of dental restorations. Part III. The concept of the geometry of proximal margins, Journal of Prosthetic Dentistry, 22, pp. 333-345.

[8] Ramsay, J.G. (1967). Folding and Fracturing of Rocks, Mc Graw Hill Book Company, 568.

[9] Obert, L., Duvall, W.I. (1967). Rock mechanics and the design of structures in rock / Leonard Obert, Wilbur I. Duvall, Wiley.

[10] Tarasov, B., Potvin, Y. (2013). Universal criteria for rock brittleness estimation under triaxial compression, International 
Journal of Rock Mechanics \& Mining Sciences, 59, pp. 57-69. DOI: 10.1016/j.ijrmms.2012.12.011

[11] Kahraman, S. (2003). Corrigendum to: "Correlation of TBM and drilling machine performances with rock brittleness, Engineering Geology, 67, pp. 269-283. DOI: 10.1016/S0013-7952(01)00137-5

[12] Altindag, R. (2002). The evaluation of rock brittleness concept on rotary blast hole drills, Journal- South African Institute of Mining and Metallurgy, 102(1), pp. 61-66.

[13] Li, Q.H., Chen, M., Jin, Y., Wang, F.P., Hou, B. (2012). Indoor Evaluation Method for Shale Brittleness And Improvement, Chinese Journal of Rock Mechanics \& Engineering, 31 (8), pp. 1680-1685.

[14] Tarasov, B.G., Potvin, Y. (2012). Absolute, relative and intrinsic rock brittleness at compression, Mining Technology, 121(4), pp. 218-225.

[15] Xia, Y.J., Li, L.C., Tang, C.A., Li, X.Y., Ma, S., Li, M. (2017). A New Method to Evaluate Rock Mass Brittleness Based on Stress-Strain Curves of Class I, Rock Mechanics \& Rock Engineering, 50(5), pp. 1-17.

DOI: $10.1007 / \mathrm{s} 00603-017-1174-6$.

[16] Altindag, R. (2009). Assessment of some brittleness indexes in rock-drilling efficiency, Rock Mechanics \& Rock Engineering, 43(3), pp. 361-370.

[17] Hucka, V., Das, B. (1974). Brittleness determination of rocks by different methods, International Journal of Rock Mechanics \& Mining Sciences \& Geomechanics Abstracts, 11(10), pp. 389-392. DOI: 10.1016/0148-9062(74)91109-7.

[18] Meng, F., Zhou, H., Zhang, C., Xu, R., Lu, J. (2015). Evaluation Methodology of Brittleness of Rock Based on PostPeak Stress-Strain Curves, Rock Mechanics \& Rock Engineering, 48(5), pp. 1787-1805.

DOI: $10.1007 / \mathrm{s} 00603-014-0694-6$.

[19] Chen, G., Zhao, C., Wei, T., Wang, J. (2018). Evaluation method of brittle characteristics of rock based on full stressstrain curve and crack initiation stress, Chinese Journal of Rock Mechanics \& Engineering.

[20] Wang, Y., Li, X., Wu, Y.F. (2014). Research on Relationship Between Crack Initiation Stress Level and Brittleness Indices for Brittle Rocks, Chinese Journal of Rock Mechanics \& Engineering.

[21] Hucka, V., Das, B. (1974). Brittleness determination of rocks by different methods. International Journal of Rock Mechanics \& Mining Sciences \& Geomechanics Abstracts, 11(10), pp. 389-392.

[22] Tarasov, B., Potvin, Y. Universal criteria for rock brittleness estimation under triaxial compression. International Journal of Rock Mechanics and Mining Sciences, 59, 57-69.

[23] Rickman, R., Mullen, M.J., Petre, J.E. (2008). A Practical Use of Shale Petrophysics for Stimulation Design Optimization: All Shale Plays Are Not Clones of the Barnett Shale; proceedings of the Spe Technical Conference and Exhibition.

[24] Lawn, B.R., Marshall, D.B. (2010). Hardness, Toughness, and Brittleness: An Indentation Analysis, Journal of the American Ceramic Society, 62 (7-8), pp. 347-350. DOI: 10.1111/j.1151-2916.1979.tb19075.x.

[25] Quinn, J.B., Quinn, G.D. (1997). Indentation brittleness of ceramics: a fresh approach, Journal of Materials Science, 32, pp. 4331-4346. 